\title{
Recognition of Prior Learning and the development of the Library and Information Service profession in South Africa
}

\author{
Peter G Underwood ${ }^{1}$ \\ Centre for Information Literacy, University of Cape Town, Private Bag, RONDEBOSCH 770I South Africa \\ pgunderwood@ched.uct.ac.za
}

Received I th October 2002

The Recognition of Prior Learning (RPL) is defined and discussed, then identified as an opportunity for the Library and Information Association of South Africa (LIASA) to enhance professional recognition and the development of its members. It discusses some of the practical and other consequences of taking this opportunity.

\section{Preamble}

This paper was prepared at the request of the Research, Education and Training Interest Group (RETIG) of the Library and Information Association of South Africa (LIASA).

The document should not be construed as policy, official or otherwise, of LIASA; nor is it indicative of policy directions that are to be taken. Rather, it identifies the Recognition of Prior Learning (RPL) as an opportunity for LIASA and discusses some of the practical and other consequences of taking this opportunity.

The purpose of the document is to provide a framework for discussion, by presenting a concept. During the course of its preparation, the author has read many experiences of RPL and has come to recognise that what is ostensibly a simple concept has many subtleties; moreover, its implementation is, almost universally, recognised as being difficult but worthwhile. What follows is, necessarily, a distillation of ideas, set within the context of South Africa - for what has become apparent is that no single model from elsewhere in the world can be adequate for the conditions here.

The document will have served its purpose if it assists people to think about RPL and how it might be implemented. It is not, in itself, a blueprint but, merely, one person's view of what might be feasible.

\section{What is RPL?}

"Recognition of Prior Learning" (RPL) is a term recognised in South Africa to mean "practices developed within education and training to identify and recognise adults' previous learning" (Research and Development Project, 2000).

Harris has defined RPL as:

a way of recognising what individuals already know and can do. RPL is based on the premise that people learn both inside and outside formal learning structures (including learning from work and life experience) and this learning can be worthy of recognition and credit (Harris and others, 1994:2).

Terms that have gained currency in other societies are:

- Accreditation of Prior (Experiential) Learning (AP[E]L) - a term used in the United Kingdom

- Prior Learning Assessment (PLA) - a term used in the United States of America

- Prior Learning Assessment and Recognition (PLAR) - a term used in Canada.

Although there are many definitions, all agree that the core notion is that learning is not only experienced through formal education: it can also be acquired through experience and in informal or non-formal settings. The contention is that such learning can be valuable to an individual and to the community within which that individual lives and works. As such, then, if education is conceived as improving the social and economic capacities of an individual, such "prior learning" can be recognised as contributing to this development. As a further step, it is suggested that it "can and should be recognised and accorded currency within formal education and training frameworks" (Research and Development Project, 2000).

There is also agreement that RPL can take two distinctive forms:

- recognition of prior accredited learning this involves assigning a credit value to the previous formal qualifications obtained by an individual. It depends upon there being an agreed and standardised scale of credits for existing and future qualifications.

I. Peter G. Underwood is Professor of Librarianship and Director, Centre for Information Literacy University of Cape Town, South Africa. http://www.ched.uct.ac.za/cil/dils/. This article is revised from a paper presented by the author at the LIASA Conference on $30^{\text {th }}$ September $-4^{\text {th }}$ October 2002 in Port Elizabeth. 
- recognition of prior experiential learning

this involves designing means whereby learning gained from experience of life and work can be evaluated and compared to an agreed and standardised scale of credits.

\section{Why might it be important in South Africa?}

There are many adults in the population who, because of past inequities, have been denied the opportunity to gain advancement in several sectors of the economy, notably to gain entry to formal education or to improve existing qualifications. The National Plan for Higher Education (Ministry of Education, 200I) identifes RPL as one of the avenues to be developed in higher education as a means of addressing both barriers.

Similarly, the South African Qualifications Authority (SAQA) has recently explored the role of RPL in relation to formal qualifications and the maintenance of quality. In a telling comment, SAQA indicates the difficulties that may be encountered: "Currently RPL amounts to rhetoric as we do not yet have a viable implementation strategy. It has been employed in some industries and it has succeeded, but this is not yet wide-spread enough. Ultimately the NQF [National Qualifications Framework] is not only about how many jobs it has created, but also about rapid and sensible transformation so that we can make a difference in the lives of the millions of learners in South Africa" (Isaacs, 2000:63).

The Council on Higher Education also identifies RPL as being significant, but difficult to implement: in particular, it considers recognition of prior experiential learning to be intrinsically problematic (Council on Higher Education, 2001:103).

\section{The nature of a profession}

The protection of members and the guarding of "trade" secrets are sometimes seen as the essential characteristics of a profession. To those aspiring to carry out the work embraced by a profession, it can sometimes seem as if the purpose of a professional grouping is solely one of the self-interest of its accredited members and the effective exclusion of those who are not members. Although this may be a cynical view, there are several examples of "protectionist" stances lasting for many years: the reluctance by the medical profession, in the early part of the twentieth century, to recognise psychiatry is an instance.

On one level, such responses can be seen to be recalcitrant, obstructing a natural development even as better understanding is gained. On the other, however, there is a vital role that society expects of a profession: the protection of members of society from charlatans and incompetence. If professions move slowly to recognise new developments, it may be because such developments are unproven, not yet shown to be safe or, as yet, well understood.

Professions also exercise "quality control" on behalf of society by validating qualifications, approving testing and examination procedures, enforcing a code of conduct and disciplining members who transgress. To practise, one must be a member of the appropriate professional body. In this, professions perform a vital role where expert opinion and knowledge is one essential component in declaring a person fit to advise, represent and affect the lives of clients who are not in a similar state of knowledge.

An extension of this role is the monitoring by professions of social, technological and other developments and, if considered necessary, to make representation to governments or other suitable bodies.

The distinguishing characteristic of a profession is some constituted body that is recognised as being appropriate and is governed by people competent in the profession who (ideally) can set aside self-interest.

\section{Does librarianship and information work constitute a profession?}

In many countries, the practice of librarianship and information work does exhibit most of these characteristics. Thus, in the United Kingdom, the Chartered Institute of Library and Information Professionals (CILIP), formed out of a merger between The Library Association and the Institute of Information Scientists, has a code of conduct, represents and disciplines its members and frequently comments publicly on developments in information management; its advice is sought by government and other bodies and it lobbies or seeks discussions with government, when appropriate. It is also a "Chartered" body, meaning that it maintains a list of those members considered by qualification and experience to be competent to practise the profession. It has also intervened on several occasions where professional malpractice seems to have occurred or where an employing organisation has acted in ways that are considered deleterious to the proper management of information in society. However, CILIP is not a Trade Union and sharply distinguishes between its role and that of a Trade Union.

There is not, however, a requirement of membership of CILIP, or even Chartered status, for a person to practise in the United Kingdom as a librarian or information manager. In this respect, then, librarianship and information management does not have the same degree of control and validation as found in, for example, the medical and clerical professions. Some, for this reason, regard it as a "semi-profession". 
Librarianship and information work in South Africa is not yet able to claim a strong professional body, though LIASA has many of the characteristics and is clearly planning for this role. The present debate about qualification structures and RPL is of considerable importance for such plans, because it is partly through its developing educational role and its role in speaking for the integrity of professional policies and procedures that it can seek to exercise the kind of influence that professional bodies extol.

One aspect of this development is vital: the establishment of a "code of conduct". Its adoption of a code of conduct at the Annual General Meeting of 2002 is a welcome move towards enhancing the status of LIASA as a professional body entrusted with a social role. The code provides a profile of professionalism - what it means within the domain of librarianship and information management to behave "professionally" - and thus begins to define the traits, modes of behaviour and competencies that experiential learning can provide.

A code of conduct can sometimes be viewed as a restrictive document, essentially outlining the obligations of the practitioner without necessarily revealing what the client might reasonably expect from the service offered. To counter this, several countries, professional groups and organisations have developed "citizens' charters" appropriate to particular qualities of life such as freedom of access to information, quality of service and impartial treatment. The codification of good practice makes it easier to identify the mix of accredited and experiential learning that would be appropriate for practitioners.

\section{The "assemblage" of a profession}

When describing people as "professionals", we mean that in their working lives they exhibit traits of behaviour that give clients confidence, a depth of knowledge that provides a coherent context for their statements and skills appropriate to the technology in use. Thus, "professionalism" depends on an assemblage of study, experience and on character traits. One sometimes hears a person described as a "born teacher": by this is meant that, along with knowledge of subjects and of educational techniques, such a person has an empathy and a depth of feeling that evokes acceptance in students.

One sometimes encounters people for whom the standards of behaviour expected of a competent professional librarian are instinctive: they are people who combine a natural curiosity with an ability to listen, and then have the capacity to imagine and place themselves in the "mindspace" of an enquirer; couple these traits with the competence in the skills of information technology, and one has what Ernest Savage memorably called "service in breadth and service in depth". The point made by Savage is that a public library, for example, is a portal to information sources, some of which are immediately available and some of which are only accessible through the network formed by libraries and information services. The professional librarian and information manager provides competent guidance: the "born librarian" encourages engagement with the resources. The ideal encounter for an enquirer is to find both characteristics in the same person.

The importance of professional training needs to be understood. If libraries are to serve as "portals to information" then the staff managing and providing those services should, ideally, have a good general knowledge coupled with an excellent professional knowledge about information sources and services. Access to the network of sources and services, which so characterises the profession, is important because it is this that supports the service that the lone individual can supply. A characteristic of reflective practitioners is an awareness of their own limitations, coupled with knowledge about how to pass an enquiry (or an enquirer) on to someone who can better assist. Anyone, whether professional, paraprofessional or simply equipped with experience of life, can provide the empathetic circumstances that encourage enquirers to articulate and develop their requests; it is the trained professional who can view the request in the context of immediately-available information sources and make judgements about whether these will be adequate or whether the search needs to be extended to other sources.

Within the developing society of South Africa, there are many communities for which the use of anything other than indigenous sources of information has been impossible or impracticable. The expansion of the network of public libraries and civil information services, the continued development of school libraries and re-configuration of higher education could have a profound and beneficial effect on access to information, especially when coupled with the fast development of reliable electronic networks. The effective use of critically-assessed information is going to be a vital component in social development and one with which the profession must engage. This means, in turn, that ensuring that communities have access to practitioners with the necessary skills and empathy is going to be an important role for the profession. Within many communities, the role of the librarian and information manager may require the skills of animateur, encouraging social development and engaging with the aspirations and needs of the community. This is a much more "proactive" role than has traditionally been recognised and one that would not necessarily be recognised as being appropriate in other countries. 


\section{The experience of other countries}

Several countries have extensive experience of RPL; it can be instructive and useful to explore this experience, but one must be cautious of importing RPL practice from elsewhere. The response of each country to RPL reflects a particular point in its own social development, this embracing a mix of social and economic pressures, educational frameworks and national imperatives. The success of RPL in a particular country will depend to a considerable extent on how well the RPL framework addresses these social pressures, is understood within the society and is coherent with the experience of the people it most affects.

South Africa can be regarded as a country that is working towards social cohesion within a democratic framework. The divisive structures of the past continue to exercise a baleful, if declining, influence, however: the history of repression and enforcement of disadvantage through resource allocation is long and its effects will take many years to negate. In this sense, then, South Africa represents a unique circumstance.

There are, however, some consistent views that emerge from a study of the literature. The first is that RPL is used to address the needs of two groups:

- those previously unable to enter higher education - RPL is used to gauge the suitability of a programme for individuals, based upon their preparedness. This judgement may take account of accredited as well as experiential learning.

- to provide credit and exemption from some of the academic requirements of a particular programme. This usually focuses on the extent to which the candidate has already achieved the learning outcomes of modules or elements

within the programme. It is strongly linked to the "articulation" of a framework of educational qualifications, allowing a person to move from one qualification ladder to another. This has become increasingly important in a culture where the working lives of people may embrace several different kinds of career, as well as levels of work.

The second "truth" is that a capacity for self-reflection is perceived to be evidence of a mature mind, one that is prepared for further, more advanced, study. Therefore, many RPL approaches depend upon the candidates being made aware of learning outcomes already assumed as part of the pre-requisite for a programme and describing their own experience before reflecting on how, and to what extent, this meets the learning outcomes they are required to have. From this, some assessment of preparedness can be made and, critically, it provides a benchmark for guiding a candidate as to what further preparatory experience may be necessary.

The third "truth" is that ad hoc arrangements for dealing with RPL, lacking agreed procedures and scales of credit ratings, are not easily sustained and, over the course of time, produce manifestly different levels of interpretation, private judgement and other anomalies. RPL must be backed by formalised and clear procedures that are the product of rational argument.

\section{Implementation}

The challenge for the LIS sector in South Africa is how to interpret and weigh the "assemblage" of competencies and skills, especially in view of the differing values that may be placed upon competencies within the sector. Thus, the domain of the public library might value knowledge of the popular reading culture more highly than knowledge of business processes; conversely, the domain of the commercial information service might value business knowledge more highly. The assessments of skills may be easier to manage, especially if candidates are able to present certificates of attendance or, preferably, earned "credits" for these areas; short courses for acquiring computer competence, telephone technique and other practical workplace skills are widely available. Similarly, professional skills could also be assessed through credit accumulation by undertaking courses offered by reputable organisations, including professional bodies and educational institutions.

The role of a professional association such as LIASA will be crucial. Firstly, it must have a strong role in defining the "assemblage" of competencies and skills that information workers will be expected to have in order to be regarded as fully, and suitably, educated to practise. Such a checklist provides a means of measuring and assessing the "training gap" that the profile of an RPL candidate may present.

There will be several levels of assemblage but, for the present, it will be enough to define the "para-professional" and the "entry-level professional" levels; this is because the immediate pressure for recognition seems strongest at these points of the promotion ladder. It is questionable whether additional, higher, levels need to be defined, because there are unlikely to be many candidates for senior professional status trying to enter through an RPL route.

There is a much stronger case for defining a "library assistant" level, however: the aim of this would be to provide a baseline for eventual development of suitable individuals to paraprofessional status and to provide a clear path for those aspiring to professional status.

Secondly, a professional body will have a strong role in auditing and validating qualifications and courses in terms of acceptability, credit value and integrity. In this respect it is most likely to operate on behalf of SAQA as the "competent body" to develop standards for the LIS sector. A first step has already been taken in that LIASA has sought to register a 
Standards Generating Body (SGB) for library and information science with SAQA. RETIG members will play a major role in the work of the SGB, but must also call on professional opinion from the wider membership of LIASA and other qualified individuals.

An aspect of the work of LIASA, which may gain some importance in view of developing labour mobility, is the accreditation of non-South African qualifications. Both the American Library Association and The Library Association of the UK have developed policies of considering the profile of individuals requesting professional recognition in these countries, rather than validating qualifications from overseas.

\section{Strategies}

Earlier, it was noted that one of the characteristic roles of a professional body is the maintenance of a list of "qualified" members. It was also noted that a characteristic of a professionally-qualified person is an integration of professional education, skills and experience. The need for RPL provides an opportunity for the development of the status of the profession by de-linking the professional status of an individual member and that member's professional education.

How would this work? All candidates for "recognised" status (whether it be at the level of "assistant", "paraprofessional" or "professional") would, in essence be "RPL" candidates, each bringing a level of certification. For "recognition", each candidate would be required to produce a "development" report in which the capacity to reflect on (as distinct from describing) current and previous experience would be required. This evaluative report would form the "integrating" mechanism.

Thus, a candidate for paraprofessional status might bring a set of certificates showing attendance and, preferably, credits accumulated from such courses. A body, such as LIASA, would then evaluate and "score" the candidate's record of prior learning and compare it with the score defined as the minimum for paraprofessional recognition. The outcome of this process would be twofold: an indication of the extent to which the candidate already had the necessary prerequisites and a training profile indicating what more was required. Thereafter, a candidate would be advised on how to obtain the required additional credits. The final process, following any additional training required, would be for a candidate to present a "report on experience", to indicate a mature understanding of what LIS work entails. This approach was adopted in the UK by The Library Association and its successor, CILIP; despite several "teething troubles" it is recognised as being of significance in developing a mature understanding of LIS work (Robertson, 2000); there is also a body of experience on writing such reports (Atton 1994a, 1994b, 1995; Cox, 1996; Wood, 2000), an e-mail discussion list (liscilip-reg, September 1998 ---) and a Career Development Group (2002) that provides advice, courses and support materials for those engaged in this task and continuing professional development. The high and low points of the experience are well summarised by Lewis (2000).

The role of a suitably-qualified "mentor" can be vital in the development of a person new to LIS work. It has long been recognised as "good practice", during the period of initiation into a new job, for the entrant to have a source of reference and a "sounding board" against which ideas can be tested (Fisher, 1996). Mentoring assists in development of confidence and competence and, in passing, also assists the mentor to perceive new aspects of the job through the comments of the new entrant (Taylor, 1999; Love-Rodgers, 2000). Where the "report on experience" idea has been adopted, it has often been coupled with the nomination of a mentor; even in circumstances where the new entrant might be working substantially alone, it has been found desirable to find someone of appropriate status to act as mentor.

For this to work, it will be necessary for LIASA to appoint a "Professional Board" to work with RETIG; its relationships with other groups within LIASA will be important, but it should be so constituted that it is answerable only to the LIASA Council, this because it will be exercising "quality control" on behalf of LIASA and the public. It would also be responsible for developing a LIASA Code of Conduct and then considering any cases of infraction of this Code.

The Board members need not be the only LIASA members who assist in the mentoring and evaluation of prospective entrants. One way of building the sense of profession is to involve the wider membership in assessment and recommendation against agreed scales of value for skills and experience; the Board would consider recommendations from this process, consider special cases in some detail, and then indicate whether a person was considered to be at a suitable stage to seek "recognised status". This latter stage would consist of nominating a mentor - or delegating this task to a local librarian in good professional standing - and eventually considering the "reflective report" produced by the aspirant. This could be coupled, if considered necessary, with an "oral scrutiny" of candidates. Experience suggests that, because the number of entrants to LIS work is fairly low, the tasks of supervision and assessment would not be overwhelming, especially if these were managed by the LIASA branches. 


\section{Conclusion}

The "assemblage" of professional status is well-captured in a recent statement by CILIP:

Academic qualifications provide evidence that people are aware of the core principles of information work and the various contexts in which they operate. But they don't necessarily guarantee aptitude for information work - and once you've graduated, the world moves on very fast indeed. Chartered Engineers, Chartered Accountants and Chartered Surveyors all have qualifications that demonstrate their professional competence ... A [professional qualification] after your name shows that you have gained formal practice-based recognition of your skills in addition to your academic qualifications (Chartered Institute of Library and Information Professionals, Career Development Group, 2002).

\section{References}

Atton, C. 1994a. The professional development report: a writer's guide. Assistant librarian, 87(6):94-95.

Atton, C. 1994b. The professional development report: a writer's guide part 2: themes and variations. Assistant librarian, 87(8):118-119.

Atton, C. 1995. Writing the professional development report. Assistant librarian, 88(1):8-9.

CHARTERED INSTITUTE OF LIBRARY AND INFORMATION PROFESSIONALS (CILIP). 2002. Chartering. [Web page] Available: $h t t p: / / w w w . c i l i p . o r g . u k / q u a l i f i c a t i o n s / c h a r t e r i n g . h t m$ [5 September 2002].

CHARTERED INSTITUTE OF LIBRARY AND INFORMATION PROFESSIONALS, Career Development Group. 2002. Chartership. [Web page] Available: http://www.careerdevelopmentgroup.org.uk/charter.htm [5 September 2002].

COUNCIL ON HIGHER EDUCATION. 200I. A new academic policy for programmes and qualifications in higher education: discussion document. Pretoria: Council on Higher Education.

Cox, A. 1996. Web resources for the PDR [Professional Development Report]. Assistant librarian, 89(10): 158-159.

Fisher, B. 1996. The development of information professionals through mentoring. London: British Library Research and Development Department. [BLRD report 6228].

Harris, J. and others. 1994. RPL international models: NTB Working Group report. Cape Town: National Training Board.

Isaacs, S. B. A. 2000. The potential for ETQAs: a workshop presented by SAQA in Pretoria on 12 October 2000: conclusion. SAQA bulletin 4(2):62-63. [PDF file] Available: http://www.saqa.org.za/html/publications/pubs/bulletins/bullvol4-2f.pdf [site visited 20 September 2001$]$.

Lewis, N. 2000. Time for reflection: the Associateship experience. [Web page] Impact: journal of the Career Development Group,

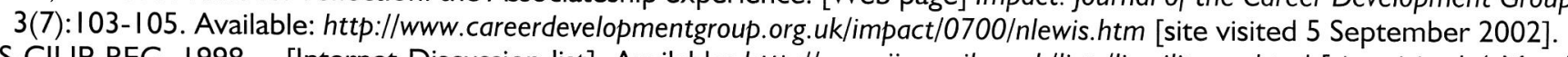

LIS-CILIP-REG. 1998 -- [Internet Discussion list]. Available: http://www.jiscmail.ac.uk/lists/lis-cilip-reg.html [site visited 4 March 2002].

Love-Rodgers, C. 2000. Chartership support page - Mentoring: what's in it for me? Impact, the journal of the Career Development Group, 3(10): 160-161.

MINISTRY OF EDUCATION. 200I. National plan for higher education. [Web page] Pretoria: Department of Education. Available: http://www.polity.org.za/govdocs/misc/higheredul.htm [site visited 5 September 2002].

RESEARCH AND DEVELOPMENT PROJECT IN THE RECOGNITION OF PRIOR LEARNING. 2000. The Recognition of Prior Learning (RPL). [Web site] Available: $h t t p: / / w w w . e l . u c t . a c . z a / r p l / w e l c o m e . h t m$ [site visited 20 September 200I].

Robertson, L. 2000. Chartership: a candidate's perspective. [Web page] Impact, the journal of the Career Development Group, 3(4):60-6I. Available: http://www.careerdevelopmentgroup.org.uk/impact/0400/ChartershipLorna.htm [5 September 2002].

Taylor, V. 1999. Mentoring: a key resource to develop professional and personal competencies. Information outlook, 3(2): 12.

Wood, K. (editor). 2000. A Chartership reader. London: Career Development Group of The Library Association. 